DOI 10.22363/2313-1683-2021-18-3-650-658

\title{
Book Review of Jay, M. (2021). The Defining Decade. New York: Twelve
}

\author{
Louie Giray \\ Polytechnic University of the Philippines, \\ Lower Bicutan, Taguig City, 1630, Republic of the Philippines \\ $\checkmark$ pupgiray@gmail.com
}

There is a prevalent notion in society that thirty is the new twenty. This dismisses the most transformative years of a person - it gives a connotation the twenties do not matter. Hence, if such thinking continues to prevail, it can give twentysomethings a wrong message - such decade is disposable. Jay strongly asserts that such thinking is wrong. According to her, it is the most defining decade of

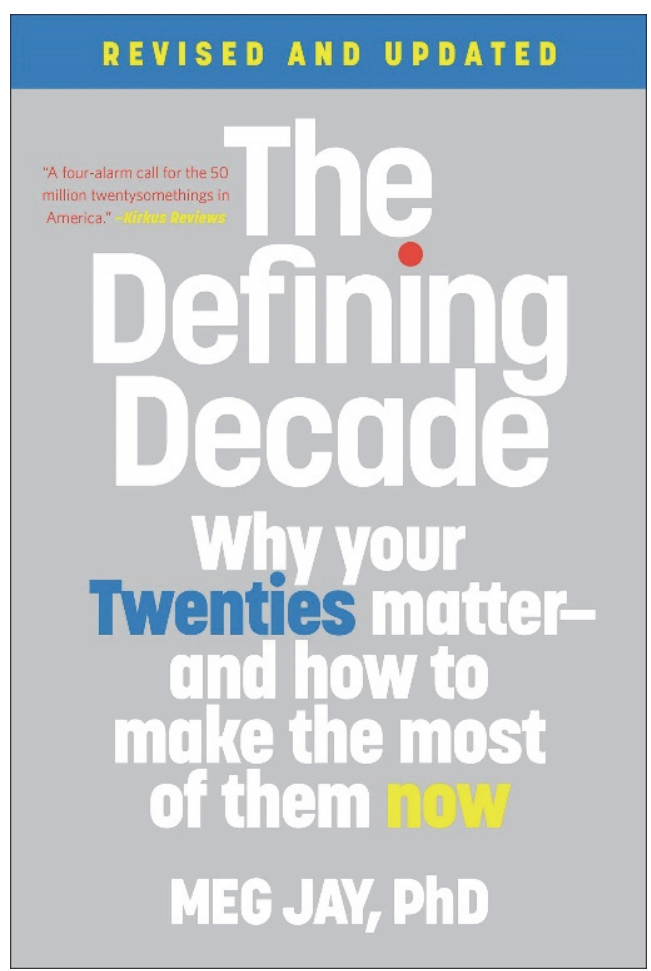
adult life. If people and society diminish such stage in life, it will cost a huge toll in the succeeding decades.

Dr. Meg Jay is a clinical psychologist, specializing in adult development especially among the twenties. Also, she is an associate professor at the University of Virginia. She maintains a private practice in Charlottesville, Virginia. Jay identifies a surge of self-creation when we leave home or finish college and become more autonomous. And those times generally happen during the twenties. It may feel that search the decade is not consequential, but they really are. They are defining and hence the book is called The Defining Decade.

Comprised of 17 chapters, this book is dedicated to twentysomethings who feel uncertain and anxious about their current and future lives, work, and relationships. Through this book, she urges the twentysomethings to reclaim their status as adults and take seriously this critical period in their lives because small things can become a radical change in the future. She believes that this pivotal time must not be wasted for it has an enormous effect.

(C) Giray L., 2021

(c) () This work is licensed under a Creative Commons Attribution 4.0 International License https://creativecommons.org/licenses/by/4.0/ 
Chapter 1. Identity Capital. Here, the author shares her personal narrative to introduce the concept of identity capital, which refers to the resources one has; it can be seen on a resume, while others cannot. Identity capital is one's array of assets which is valuable in the marketplace, as well (Côté, 2002). It can in can be on their mental models, how they bring themselves, and how they communicate, etc.

She mentions a conclusion from research which states that underemployed twentysomethings are more depressed and unmotivated than unemployed ones. But before choosing to become unemployed, she also reveals another research that states that unemployment is associated with depression and heavy drinking in thirties even after having a regular job. She urges them to take a job with the most capital - a job will make them improve. She also mentions an advice from a thirty something which is to experiment more with work and to act more than wish. Indeed, the first and only way to discover out what to do in life is to do something.

Chapter 2. Weak Ties. According to the author, urban tribe - family, close friends - are overrated. Surely, they help us when we are sick or in need of companionship. But when seeking a job, the most helpful are the ones we barely know, otherwise known as weak ties (Aral, 2016). They already people we have met or we somehow connected to but did not level up to being close friends. Examples are coworkers and neighbors. We seldom talk to them.

Strong ties may offer sympathy and connection, but weak ties have something to provide also. Since they are different from us, then we can get a fresh perspective; they also know people and information that our strong ties do not know. Hence, it can become an opportunity. Strong ties share the same language and worldviews, while weak ties do not. Therefore, if we communicate with the latter, then we put ourselves in a place of difference. We know that they do not think the same as us and so we try to elaborate. This can also help us grow and change.

Chapter 3. The Unthought Known. Jay cites uses Christopher Bollas's unthought known, which refers to the knowledge about ourselves that we somehow forget - it can be dreams, aspirations, or truths we sense we do not express to others and we silently keep to ourselves (Bollas, 2017). We do not tell these matters to others because it might be viewed negatively and it may mean our lives. Twentysomethings have a lot of options; in the world of many opportunities, they seemingly can do whatever they want or walk in any path, amplified by the general advice of adults. The author thinks that such banal counsel is not helping them and instead does the opposite - it just makes them do not take actions and feel worried and anxious.

Some twentysomethings just rely on other people or a group concerning their decisions and actions in life. They are just easily swayed by the environment they are in and hence they do not make any deliberate action in alignment with their own values and aspirations. Meanwhile, other twentysomethings just do make actions and are just thinking of things they want or aspire. They become uncertain and plan overly, driving them to the situation where do they no do not make any concrete moves to reify their decisions. In reality, the real uncertainty comes when real actions are made. Regrettably, uncertainty multiplies when they do not know how to achieve their decisions.

Chapter 4. My Life Should Look Better on Facebook. Facebook and other social media platforms are utilized by twentysomethings as a tool for social comparison. Jay postulates they spend a lot of time examining profiles of other Face- 
book friends which can make them in return feel bad about themselves and their achievements.

Unbeknownst to them that these people on social media just post good things and highlight positive moments in their lives and hide their problems and troubles (Appel et al., 2016). This makes them feel alone, helpless and unconnected. Many twentysomethings use social networking sites not to catch up with friends but to keep up with them. They feel that they are supposed to achieve what some people on the social networks have achieved.

Chapter 5. The Search for Glory and the Tyranny of the Should. Some twentysomethings dream big and grandiose, as repeatedly advised by adults. Meanwhile, other twentysomethings sell themselves short and hence dream small. Part of realizing the actual potential is to understand first their gifts and limitations and how all these fit with the world. From there, authentic potential shall start. The author cites Karen Horney's search for glory. It pertains to the tendency to lean on what is ideal than what is real (Horney, 1950). Contributory to this are parents and society. Their parents may be urging twentysomethings to get a career that has a lucrative salary, or their peers are telling them to go to the path of fame.

Many twentysomethings are not clear if their goals are leading them to their potential or they are just searching for glory. The latter can be detected through sentences with supposed to's or should's. This masquerades as high standards or authentic goals, but they are not the same. Goals feel like genuine dreams while shoulds are oppressive obligations. Shoulds just make things black-and-white and that if it is not achieved, the person is either a winner or a loser.

Chapter 6. The Customized Life. Many twentysomethings face a lot of possibilities. They think that they can be anything they want. This might sound a liberating fantasy, though it can be disorienting and overwhelming. To them, the notion of anything should sound limitless. However, conforming to a conventional nine-to-five job sounds very limiting. There is apprehension about repeating the same thing. The author, though, does not completely go against the idea of a unique life. She understands that distinctiveness is a fundamental part of identity. Many twentysomethings define themselves as not this-or-that, but it should not end there. There is a need for a shift from negative to affirmative self-definition. This takes courage which is a braver form of self-definition. Many twentysomethings think that if they claim a career, it would be saying to a status quo forever. It means saying no to other interesting things in life.

However, according to the author, if twentysomethings will not agree to a career, they will not be able to start and their lives will be limited and unremarkable. The focus of the author is on starting. She does not want them to end up with blank resumes. She mentions it is like a customized bike. It should start with common parts like wheels. From there, one can uniquely design a unique bike. The same logic applies to their lives, which can be personalized as what they want if they first start with something common like an office job. She suggests that the first step is to establish a professional identity. The next step is to claim a story about interests and talents. She says twentysomethings are more still of being a potential than proof and so telling a good story of their identity is a great edge.

Chapter 7. An Upmarket Conversation. According to the author, many twentysomethings do not think much about marriage; they concentrate more on 
career. In fact, they spend more time in life being single, in comparison to preceding generations. Many of them plan about their careers well but, unfortunately, not their marriage. Others apparently do not think much about it. This is alarming, Jay asserts, because marriage can profoundly change various aspects of our lives, a very defining milestone. Many of them, especially the ones who have fast-paced lives in high profile jobs just whisper and wish about their future relationships. They do not talk about that to others because they think of that as politically incorrect or being so strategic. Such superstitions reinforce the notion that they do not have any control of their relationships. Hence, they just leave it to destiny.

Jay also discusses the prevailing thought of age thirty deadline. Many twentysomethings just routinely go with life, barely thinking about marriage. When they hit the age 30 , sudden anxiety would emerge - they would overthink and go in a hurry to find for someone to marry. She warns twentysomethings that putting something off until later does not always imply doing it better. Postponing marriage is not a good idea and will not result in a better connection. Aside from that, good relationships, like good jobs, do not arrive when they are ready; it takes a few careful attempts before we truly understand what love and dedication are.

Chapter 8. Picking Your Family. There is a prevalent notion that we cannot pick our families. That, however, I true only when growing up; the case is differrent when one partners with someone. It is the second chance to having a family. Twentysomethings tend to become wishful about family they will be in. They are inclined to thinking that there is nothing they can do about it and that is beyond their control. Picking a family may not be romantic. Nevertheless, this is a pivotal and defining act, which can affect many facets of their lives - like the here and now, but also the future.

Some of them are fearful about this, while others do not think much about their choice. It is better to be fearful than not being thoughtful at all, Jay highlights. She recommends utilizing fear as a driving force that can propel them to take love seriously. In a culture where individualism is myopically focused, there is a tendency to overlook one of the greatest opportunities that twentysomethings have - the capacity to pick and create family. In fact, this choice is life will be about and shall define the decades ahead.

Chapter 9. The Cohabitation Effect. It is often held that living together before married is a good measuring stick for a successful relationship. However, Jay refutes this incorrect assertion. Sociologists have discovered that individuals who cohabitate, or live together, are less unsatisfied with their marriage and are more likely to divorce than couples who do not (Cohan, Kleinbaum, 2002). This is referred to as the cohabitation effect. Many twentysomethings appear to be a cross between a college roommate and a partner - it is far from a genuine serious commitment between two couples. The cohabitation effect is technically a pre-engagement cohabitation not premarital. According to researchers, couples, who after engagement, live together are not more likely to suffer from distress or dissolved marriages because they have established a clear commitment, compared to those who habitat before marriage here on the other hand those who cohabitate before marriage.

Those who cohabitate prior to engagement, on the other hand, are more likely to have worse communication and a lower degree of commitment; several stu- 
dies have indicated that couples who cohabitate before engagement are less devoted before and even after marriage (Klin et al., 2004). Founding a relationship based on convenience and ambiguity can impede the process of claiming the ones we love. Twenty-somethings must be secure in their ability to choose the individuals they want to spend their time with, not because remaining together is convenient or splitting up is pragmatic.

Chapter 10. On Dating Down. Jay contends that high school and twenties are the time we have our most self-defining memories; there we start to put together stories about who we are and why. And these stories become fragments of our identity. These, in general, say something about our colleagues, family, and culture. There are also untold stories that are no less than the told ones. Commonly, they are shameful for the person. Such stories may repeat in our mind, and they contain also significant facet in one's identity. The author asserts that life stories about ruin can trap us, while life stories about victory can transform us.

Jay shares that, in in her practice, she lets her clients tell stories so that they become visible and later become the start of change. Twentysomethings who are dating down frequently have unreported or unedited stories. The stories originated from old experiences. These stories affect their present lives and can repeat in various ways. The good news is stories can be changed through forming new encounters and conversations.

Chapter 11. Being in Like. According to Jay, when it comes to dating, twentysomethings should look for commonalities. She means being similar in important ways and enjoying who the other person is. They can understand and respect one another since they are similar. She contends, based on research, that couples who are similar in age, education, perspectives, values, and intellect are more likely to be content with their marriages and less inclined to seek divorce. She does, however, add a qualifier. A good relationship requires more than just resemblance. It may bring couples together, but it does not guarantee that they will have a satisfying relationship.

Jay contends that one similarity to consider among young couples is personality, which is about who the person is. Personality, she contends, is about half inherent and half constructed. She clarifies that not all will be exactly matched in the Big Five for young couples. Nonetheless, the more similarities there, the more harmonious and the relationship may be. And for the personality differences, it is important that couples learn about them too, since it is essential why someone does things differently. This is important for bridging differences, a crucial aspect for any relationship.

Chapter 12. Forward Thinking. Jay talks about the frontal lobe which, based on science and from the term itself, is the most forward part of the brain. It is the most recent part of the brain that has evolved in humans. This area of the brain is where reason and judgment reside; it balances emotions. It also allows us to think about the both the present and the future - it is where we do our forward thinking. However, such frontal lobe is not yet fully developed yet for adolescents and twentysomethings (Steinberg, 2014)). Nevertheless, it does not mean that they are brain damaged. It is just that their frontal lobe has not fully matured. For that reason, according to Jay, are in seemingly ironic situations. For example, even they managed to go to good colleges, yet they could not know how to start their careers. 
The author contends that the school tests how we solve problems with correct answers and time limits, but being a forward-thinking adult requires one to think and act in uncertain situations. The twentysomething decade is the last critical period in which the brain overprepares for the uncertainty of adult life. Hence, Jay once again reminds, it is pivotal for twentysomethings to utilize this chance to acquire skills in career, marriage, interactions, etc. Engaging with good jobs and authentic relationships is a good way to learn the language of adulthood.

Chapter 13. Calm Yourself. When twentysomethings enter a job, which is risky or not safe, the often are shocked by the changes in the environment and culture. If before they are just fine of just going with the flow in universities with average grades, now things have radically changed. It seems that even the smallest things matter. They would be lectured about their posts on social media, typos, tone used in email, communication with superiors, among others. However, Jay indicates, the problem is very few bosses or seasoned employees want to be mentors for these newcomers in the workplace. Unfortunately, some even do not know how to be one. That is a recipe for hellish work relationships which can make twentysomethings anxious and incompetent. Those twentysomethings who are not anxious are either overconfident or underemployed.

The author incorporates the remarks of evolutionary theories on brain to better understand twentysomethings. In accordance to evolutionary theorists, our brain inherently has a novelty detector (Barceló et al., 2002). When the brain is surprised or sees a new information, the event lasts longer in the memory. Compared to adults, twentysomethings tend to remember the negative than the positive happenings in their lives. Hence, when their competence is criticized, they become angry and want to take action; that criticism is pondered for a very long time. In contrast, adults, in general, do not become highly combatant or reactive when negative information is presented.

Twentysomethings have the logic that if they quit their job, then they can feel better. It is true, but it is just a temporary relief. Jay mentions that it confirms also their fear, and such feeling might happen again in the next job. Many twentysomethings worry which prevents them from being surprised. They are in the trance of negative state in which it affects their body negatively, because of the bombardment of stress. With the recommendation of the author, it is better if they reframe the situation at work. The happenings at work cannot be controlled but attitude and interpretation can.

Chapter 14. Outside In. Confidence comes from the outside, not the inside out. It means that before one becomes confident, mastery experiences should take place. Confidence, otherwise known as self-efficacy in the jargon of research psychology, refers to the belief of a person that he has the ability to execute the task effectively and give the desired outcomes (Cast, Burke, 2002). Sadly, there are many twentysomethings who do not want to encounter many failures and hence hide from underemployment. However, they are not empowering themselves with this strategy. Real confidence at work comes from mastery tasks that are challenging and require effort. A string of easy success is fragile and can easily be shattered when failure strikes. But, more resilient confidence comes from succeeding and overcoming failures. 
Many of them are easy to give away their confidence - which they have gotten from the hardships they were able to endure, and the months and years they stayed in a company. Jay recommends viewing feedback as a learning tool and not as a means of terrorizing. Positive feedback at work may help a person feel better, whilst negative criticism might provide a chance to make things better.

Chapter 15. Getting Along and Getting Ahead. There is a vivid debate among personality researchers whether if a person's personality still changes after age 30 . While researchers contend that personality is incredibly stable after the age 30 , there are some researchers who optimistically advocated some changes in personality can happen even without the intervention of significant and catastrophic happenings. However, one thing is for sure personality is more malleable during the twenties, compared to the years before or after it (Arnett, 2000). Jay, therefore, insists that twenties are great for the development of personality. Hence, it is appropriate to utilize that opportunity to effectively empower oneself - it is a chance for transformation. Using numerous studies, Jay mentions that many twentysomethings do not feel that they are getting along or getting ahead. They feel stressed and alienated. With emphasis, she pinpoints that feeling better does not come from evading adulthood, instead it comes from venturing toward adulthood. Hence, as the author opines, they need to take actions; instead of just wishing, they must utilize their opportune time to transition from school to work and from hookups to relationships. To truly mature, they must make investments and commitments, most especially in love and work.

Otherwise known as building blocks of adult personality, goals play a crucial part in the development of twentysomethings. People become happier and more confident when they set goals. Goal setting in twenties, according to Jay, leads to better purpose and well-being in thirties. It not only helps them explain what they desire, but it may also arrange their life. Relationships, according to the author, may provide stability and maturity. Backed up with a study, she warns that those who were single throughout their twenties experienced a significant decline in their confidence during their thirties.

Chapter 16. Every Body. Many young people postpone marriage and invest more time on education and work. For them, it is not practical to have children when love and work are not figured out. Jay discusses fertility and contends that the decade in which the twentysomethings are in are the most fertile point in their lives. She says that they need to know that.

Fertility plummets as age goes by; it should be understood that for both men and women, biological clock ticks (Greenwood et al., 2003). It is a truism that many people opt out parenthood in order to focus at work or in other endeavors. On the other hand, there is a survey which pinpoints many childless couples are not childless by choice. She also states this postponing marriage leads to more stressful to more stressful lives, most especially when work or raising children to collide with the peak of earning years.

Chapter 17. Do the Math. Jay analogizes the twentysomething years as living beyond time. They are surprised after school that there is no curriculum to follow, and life opens up in an instant. For them, it is disorienting. Time and things are very different. The author also discusses that the present bias, which all people especially twentysomethings, experience. Present bias is the tendency to narrowly 
focus on the present and discount the future. People tend to favor the rewards of today for the rewards of tomorrow.

As emphasized, twentysomethings tend to especially lean on the present bias since their brains are still developing forward thinking which anticipates consequences and plans for the future. Many of them engage in now-or-never behaviors, like engaging in multiple partners and blowing off responsibilities, that they do not think much of the future. Since they believe they have infinite time, they put a lot of psychological distance to no and later, which can lead to problems. Thinking in such a way to distance that leads to abstraction and that cycle goes on.

As a young person and academic, I find this book very helpful and empowering. As I read it, there were lots of aha moments and insightful points that I did not know before. With her straightforward suggestions, it was a smooth read. This book is not a mere list of advice for twentysomethings - it is an entirely coherent work on and for twentysomethings. Free from difficult lingos in psychology, the book is easy to understand. Honestly, as a twentysomething, I was not taking matters and affairs seriously. But having read this book, enlightenment came to me and made me realize that they are consequential, as pinpointed in the book. Hence, the author is effective in making a paradigm shift for me.

I surmise that it is true as well for others also who got to read the book. The book is not deadening since vivid narratives of herself, and her clients are incorporated to concretize abstract concepts. As an academic, I recommend to professors, lecturers, and university administrators to infuse into the curricula the lessons here or better utilize the book as a resource, most especially to courses like education, psychology, personal development, sociology, and other similar disciplines. I think this will be of great help to them and will very much appreciate it because the lessons are practical and very relatable to their lives.

\section{References}

Appel, H., Gerlach, A.L., \& Crusius, J. (2016). The interplay between Facebook use, social comparison, envy, and depression. Current Opinion in Psychology, 9, 44-49.

Aral, S. (2016). The future of weak ties. American Journal of Sociology, 121(6), 1931-1939.

Arnett, J.J. (2000). Emerging adulthood: A theory of development from the late teens through the twenties. American Psychologist, 55(5), 469.

Barceló, F., Periáñez, J.A., \& Knight, R.T. (2002). Think differently: A brain orienting response to task novelty. NeuroReport, 13(15), 1887-1892.

Bollas, C. (2017). The shadow of the object: Psychoanalysis of the unthought known. Routledge.

Cast, A.D., \& Burke, P.J. (2002). A theory of self-esteem. Social Forces, 80(3), 1041-1068.

Cohan, C.L., \& Kleinbaum, S. (2002). Toward a greater understanding of the cohabitation effect: Premarital cohabitation and marital communication. Journal of Marriage and Family, 64(1), 180-192.

Côté, J.E. (2002). The role of identity capital in the transition to adulthood: The individualization thesis examined. Journal of Youth Studies, 5(2), 117-134.

Greenwood, J., Guner, N., \& Knowles, J.A. (2003). More on marriage, fertility, and the distribution of income. International Economic Review, 44(3), 827-862.

Horney, K. (1950). The search for glory. Pastoral Psychology, 1(9), 31-38.

Kline, G.H., Stanley, S.M., Markman, H.J., Olmos-Gallo, P.A., St Peters, M., Whitton, S.W., \& Prado, L.M. (2004). Timing is everything: Pre-engagement cohabitation and increased risk for poor marital outcomes. Journal of Family Psychology, 18(2), 311. 
Steinberg, L. (2014). Age of opportunity: Lessons from the new science of adolescence. Houghton Mifflin Harcourt.

\title{
Article history:
}

Received 24 June 2021

Revised 5 July 2021

Accepted 15 July 2021

\section{For citation:}

Giray, L. (2021). Book review of Jay, M. (2021). The defining decade. New York: Twelve. RUDN Journal of Psychology and Pedagogics, 18(3), 650-658. http://dx.doi.org/10.22363/2313-1683-2021-18-3-650-658

\section{Bio note:}

Louie Giray is a lecturer in Communication and Education Studies at College of Teacher Education, Polytechnic University of the Philippines, Taguig City Branch. He spearheads a research initiative whose primary aim is to hone the research skills of young scholars. His academic interests range from, but not limited to, school culture, youth development, and educational studies. ORCID: https://orcid.org/0000-0002-1940-035X E-mail: pupgiray@, gmail.com

DOI 10.22363/2313-1683-2021-18-3-650-658

\section{Рецензия на книгу: Jay M. The Defining Decade. New York: Twelve, 2021. 336 p.}

\author{
Л. Гирей \\ Политехнический университет Филиппин, \\ Республика Филиппины, 1630, Тагиг, Нижний Бикутан \\ pupgiray@gmail.com
}

\section{История статьи:}

Поступила в редакцию 24 июня 2021 г.

Принята к печати 15 июля 2021 г.

\section{Для цитирования:}

Giray L. Book review of Jay, M. (2021). The defining decade. New York: Twelve // Вестник Российского университета дружбы народов. Серия: Психология и педагогика. 2021. T. 18. № 3. С. 650-658. http://dx.doi.org/10.22363/2313-1683-2021-18-3-650-658

\section{Сведения об авторе:}

Гирей Луи, преподаватель коммуникационных и образовательных исследований в Педагогическом колледже, Политехнический университет Филиппин, филиал в г. Тагиге. Возглавляет исследовательскую инициативу, основной целью которой является оттачивание исследовательских навыков молодых ученых. Академические интересы Л. Гирея связаны с исследованием школьной культуры, развития молодежи и образования и др. ORCID: https://orcid.org/0000-0002-1940-035X E-mail: pupgiray@gmail.com 